\title{
Assessment of women's perspectives and experiences of childbirth and postnatal care using Q-methodology
}

N.P. Shabila, ${ }^{1}$ H.M. Ahmed $^{2}$ and M.Y. Yasin ${ }^{3}$

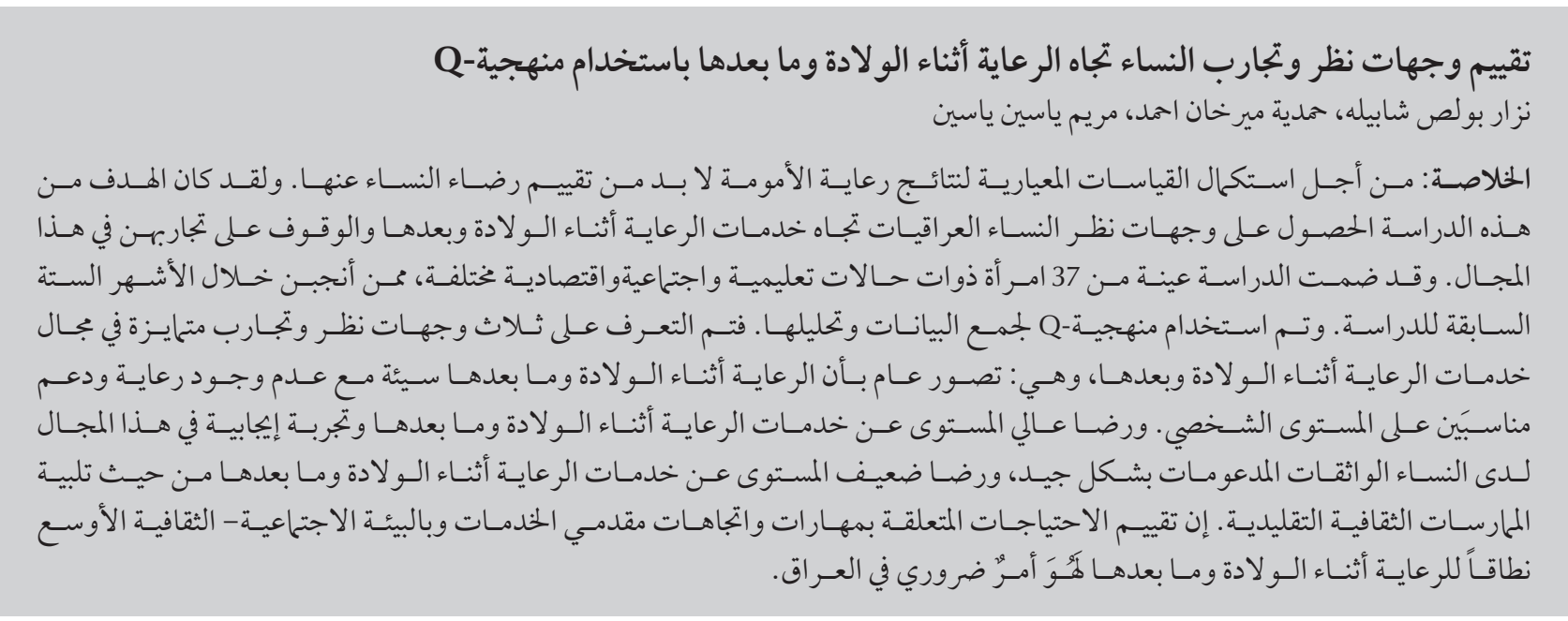

ABSTRACT To complement standard measures of maternity care outcomes, an assessment of women's satisfaction with care is needed. The aim of this study was to elicit the perspectives and experiences of Iraqi women about childbirth and postnatal care services. The study participants were a sample of 37 women of different educational and socioeconomic status who had given birth during the previous 6 months. Q-methodology was used for data collection and analysis. Three distinct viewpoints and experiences of childbirth and postnatal care services were identified: a general perception of poor childbirth and postnatal care with lack of appropriate interpersonal care and support; a high satisfaction and positive experience with childbirth and postnatal care services among the confident and well-supported women; and poor satisfaction with the childbirth and postnatal care services in terms of meeting traditional cultural practices. Needs assessment around providers' skills and attitudes and the wider sociocultural environment of childbirth and postnatal care is necessary in Iraq.

Évaluation des conceptions et des expériences des femmes en matière d'accouchement et de soins postnatals à l'aide de la méthode-Q

RÉSUMÉ Pour compléter les mesures standards des résultats des soins maternels, une évaluation de la satisfaction des femmes en matière de soins est nécessaire. L'objectif de l'étude était de découvrir les conceptions et les expériences des femmes iraquiennes en matière d'accouchement et de services de soins postnatals. Les 37 femmes de l'échantillon participant à l'étude avaient un statut socioéconomique et un niveau d'études variés et avaient accouché au cours des six mois précédents. La méthode-Q a été utilisée pour le recueil et l'analyse des données. Trois points de vue et expériences distincts de l'accouchement et de services de soins postnatals ont été identifiés : une perception générale de l'accouchement et des soins postnatals médiocre caractérisée par un manque de soins et de soutien interpersonnels appropriés ; un niveau de satisfaction élevé et une expérience positive de l'accouchement et des services de soins postnatals chez les femmes bien entourées et confiantes; et un mauvais niveau de satisfaction en termes d'accouchement et de services de soins postnatals concernant le respect des pratiques traditionnelles et culturelles. Une évaluation des besoins vis-à-vis des compétences et des attitudes des prestataires et de l'environnement socioculturel plus large dans ce domaine est nécessaire en Iraq. 


\section{Introduction}

A large proportion of the 800 maternal deaths per day are preventable $(1,2)$. There are many well-recognized effective interventions to prevent maternal mortality. However, availability, utilization, accessibility and quality of appropriate maternity care remain poor for many women. Most deaths occur due to poor service provision, as well as lack of access to and use of these services (1). Childbirth and postnatal care are among the recommended interventions for reducing maternal and newborn mortality (3). Although the traditional clinical measures of the quality of care are maternal and perinatal mortality and morbidity rates, a patient-centred measure such as women's satisfaction with care is also essential for an appropriate assessment of maternity care (4).

The Iraqi health-care system has been seriously affected during the last few decades as a result of different wars, internal conflicts, international sanctions and political instability (5-7). These damaging effects have had a particular negative impact on the availability and quality of maternity care services, which continue to suffer from serious problems $(5,8-10)$. These events caused a significant drop in the important health indices, with the maternal mortality ratio and neonatal mortality rate remaining as high as 84 per 100000 live births and 23 per 1000 live births respectively in 2010 (11).

It is increasingly recognized that one of the critical areas of the health services in Iraq that need substantial efforts in improvement is maternity care $(6,8,12)$. Effective restructuring of this important aspect of population health requires a better understanding of its problems and needs, and the obstacles to its development. Research that has examined the Iraqi maternity care services particularly from women's perspectives is very limited. Therefore, the aim of this study was to elicit Iraqi women's perspectives and experiences about childbirth and postnatal care services.

\section{Methods}

\section{Study design and setting}

This explorative study was carried in Erbil, the capital of the Iraqi Kurdistan region, from May to July 2013. The research ethics committee of Hawler Medical University approved the study.

The study employed Q-methodology, a technique for identifying unique, different viewpoints, as well as commonly shared views. Q-methodology is particularly useful in research that explores human perceptions and interpersonal relationships (13). Qmethodology effectively combines the strengths of qualitative and quantitative dimensions $(14,15)$. Typically, Q-methodology begins with a sample of statements (Q-set) that offers the fullest range of viewpoints on the study topic (16). A participant group (P-set), representing various sociodemographic groups relevant to the study topic, is asked to rank order (Q-sort) the Qset along a standardized continuum. Q-analysis involves an inverted factor analytic procedure (17-19). Correlation between personal profiles groups together participants who hold similar viewpoints or opinions. By correlating across individuals, Q-factor analysis gives information about similarities and differences in viewpoint on a particular subject (17).

\section{Sampling}

As a general guideline, Q-studies consider 40-60 participants to be adequate. However, many good studies with adequate analysis have been successfully carried out with considerably smaller number of participants. It is generally recommended to use a number of participants that is smaller than the number of items in the Q-set (20). As the final set of statements of this study was 39 statements, it was decided to select 37 women to participate in this study. These 37 women were purposively selected to include women of reproductive age who had at least 1 child not older than 6 months and who had some experience with labour and postnatal care at a public facility. Efforts weremade to selectparticipantsfrom different age groups, different educational levels and socioeconomic backgrounds and different geographical areas of Erbil city, to ensure maximum variability and diversity of respondents.

\section{Data collection}

\section{Statement identification}

To determine the issues concerning maternal health-care services 2 focus groups with 20 women were conducted, in addition to interviewing 5 women attending antenatal care facilities and labour wards and 2 nurses and a gynaecologist providing maternity care services. Statements were extracted from these transcripts. A review of the literature about Iraqi women's perspectives of maternity care services and the views of women of similar cultural background helped in compiling additional statements $(21,22)$. The details of these activities are provided elsewhere as they were also used to determine the statements for another study to assess women's perspectives of antenatal care (10).

\section{Study tool}

The statement identification step helped in extracting 110 statements related to childbirth and postnatal care. These statements were reviewed and then repeated statements were discarded, statements of close similarity were combined and viewpoints of opposite meaning were removed (7). Statements related to the different dimensions of 3 levels of Donabedian's conceptual framework for assessing quality of care were selected: structure, process and outcome (23). The statement selection step resulted in 39 statements that potentially represented different aspects of 
childbirth and postnatal cares services. Each of these 39 statements received a random number and was typed onto a small card. Later, the Q-sort of a quasinormal distribution with a specific number of cells equal to the number of the Q-sample statements was developed (Figure 1).

\section{Procedure}

The selected women were invited to participate in the study after obtaining their consent. The purpose of the study and instructions for completing the task were explained to each participant. The task of the participants was to sort the cards into 9 piles, from -4 (most disagree) to +4 (most agree), in relation to their view and experience of different aspects of childbirth and postnatal care services.

\section{Data analysis}

The Q-sorts were entered into the PQMethod, version 2.11 program and were analysed using by-person factor analysis technique (24). Centroid factor extraction and varimax rotation were used to obtain latent factors. Different factor solutions were examined and the solution where all the factors had at least 2 defining sorts and had eigenvalues more than 1.00 was selected (23). Interpretation of each factor was done subjectively through examining the characterizing statements (those with a rank value of $+4,+3,-3,-4$ ) and the distinguishing statements (a statement whose score on that factor is significantly different from its score on any other factor) $(7,17)$.

\section{Results}

The mean age of the 37 participating women was 27.1 [standard deviation (SD) 6.3] years. Table 1 shows the details of the participants' sociodemographic characteristics.

Analysis of the participants' Q-sorts resulted in having 3 distinct

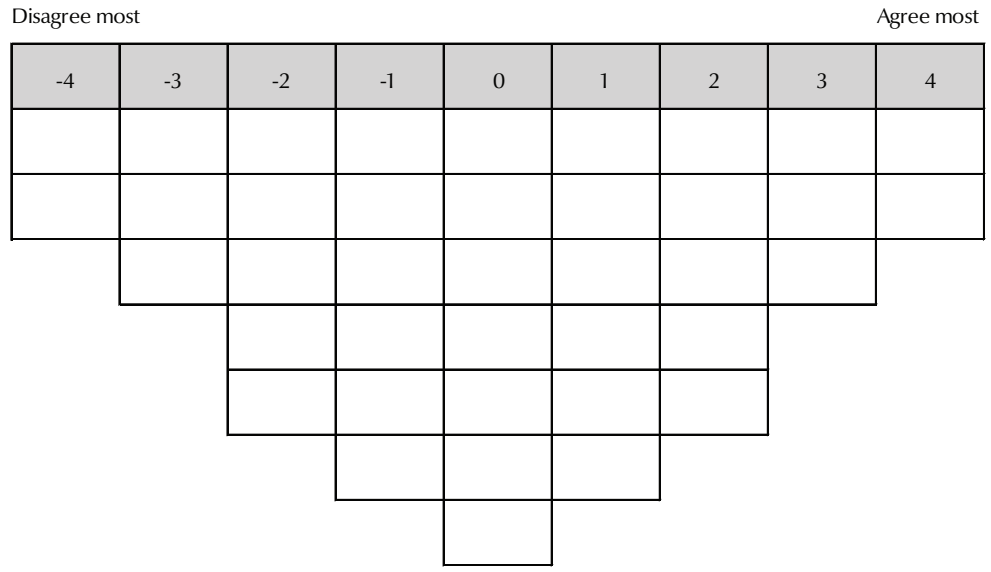

Figure 1 The Q-sort matrix birth and postnatal care services. This accounted for $61 \%$ of the variance. The 3 factors were defined by 21 women (56.8\%). Three women did not load significantly on any of the factors and 13 women loaded significantly on more than 1 factor. Table 2 shows the Q-set viewpoints and experiences of child- statements and factor arrays with scores against each statement by factor.

\section{Factor 1: Poor interpersonal care and support}

Nine participants loaded significantly onto factor 1 . They included 8 housewives, 7 residing in poor quarters in

\section{Table 1 Sociodemographic characteristics of the participants}

\begin{tabular}{lcc} 
Characteristic & No. & $\%$ \\
Age (years) & 5 & 13.5 \\
$18-20$ & 15 & 40.5 \\
$21-25$ & 6 & 16.2 \\
$26-30$ & 8 & 21.6 \\
$31-35$ & 3 & 8.1 \\
$36-40$ & & \\
Employment status & 10 & 27.0 \\
Government employees & 21 & 56.8 \\
Housewife & 6 & 16.2 \\
Student & & \\
Education level & 5 & 13.5 \\
Primary school & 11 & 29.7 \\
Intermediate school & 10 & 27.0 \\
Secondary school & 9 & 24.3 \\
Institute & 2 & 5.4 \\
College & & \\
No. of children & 11 & 29.7 \\
1 & 12 & 32.4 \\
2 & 8 & 10.8 \\
3 & 4 & \\
4 & 2 & \\
5 & & \\
\hline
\end{tabular}




\begin{tabular}{|c|c|c|c|c|}
\hline \multirow[t]{2}{*}{$\#$} & \multirow[t]{2}{*}{ Statement } & \multicolumn{3}{|c|}{ Factor } \\
\hline & & 1 & 2 & 3 \\
\hline 1 & Skin-to-skin contact occurred either immediately or soon after birth & $0^{*}$ & $3^{* *}$ & $1^{*}$ \\
\hline 2 & $\begin{array}{l}\text { While I was in hospital for childbirth, I was given enough advice and help about } \\
\text { feeding and looking after the baby }\end{array}$ & -3 & $2^{* *}$ & -3 \\
\hline 3 & $\begin{array}{l}\text { The local primary health care centre has been an important support to me after } \\
\text { having a baby }\end{array}$ & -2 & $2^{* *}$ & -2 \\
\hline 4 & If I were to have another baby, I would return to the same hospital & -1 & -2 & -3 \\
\hline 5 & My husband was the best possible help to me after the baby was born & $-2^{* *}$ & 3 & 1 \\
\hline 6 & In the labour room, the care providers respected patients and were compassionate & 0 & -2 & -1 \\
\hline 7 & $\begin{array}{l}\text { There was only one doctor in the labour ward who was in rush and was moving } \\
\text { from a patient to another }\end{array}$ & $-2^{* *}$ & $-4^{* *}$ & $0^{* *}$ \\
\hline 8 & $\begin{array}{l}\text { Having a baby boy is very important to have a better social position (respect) within } \\
\text { the family }\end{array}$ & 0 & $-4^{* *}$ & 4 \\
\hline 9 & $\begin{array}{l}\text { I never met any of the doctors or midwives who looked after me during childbirth } \\
\text { before I went to have the baby }\end{array}$ & 4 & 2 & 2 \\
\hline 10 & The staff were usually too busy at the hospital to take care of me properly & 3 & $-3^{* *}$ & 1 \\
\hline 11 & $\begin{array}{l}\text { While I was in hospital I was given enough advice and help about my own health } \\
\text { and recovery after birth }\end{array}$ & -2 & -2 & -2 \\
\hline 12 & $\begin{array}{l}\text { Overall, I was very satisfied with the care my baby and I received in hospital after } \\
\text { the birth }\end{array}$ & $\mathbf{0}$ & $\mathbf{0}$ & $\mathbf{0}$ \\
\hline 13 & There was good monitoring of patient's recovery after childbirth & $-4^{* *}$ & -2 & -2 \\
\hline 14 & More care providers are needed in the labour ward & 2 & 1 & 2 \\
\hline 15 & Childbirth has been one of the worst experiences of my life & $4^{*}$ & $1^{* *}$ & 2 \\
\hline 16 & It would have been so much better if I had had a longer hospital stay after the birth & $-3^{* *}$ & -1 & -1 \\
\hline 17 & There were adequate rooms and space in the labour ward & -1 & 0 & $2^{*}$ \\
\hline 18 & $\begin{array}{l}\text { I prefer giving birth at hospital rather than at home or with a traditional birth } \\
\text { attendant }\end{array}$ & -2 & $4^{* *}$ & -4 \\
\hline 19 & $\begin{array}{l}\text { During childbirth I was not given the information and explanation I needed and I } \\
\text { felt unable to ask questions }\end{array}$ & 1 & $\mathbf{0}$ & $\mathbf{0}$ \\
\hline 20 & Presence of the father after birth is very important & 2 & 2 & -3 \\
\hline 21 & $\begin{array}{l}\text { It is important to follow cultural traditions like protecting the baby from the evil eye } \\
\text { and eating special food }\end{array}$ & -1 & 0 & $4^{* *}$ \\
\hline 22 & $\begin{array}{l}\text { My companion and I were frequently left alone by the staff at a stage when it } \\
\text { worried me to be alone (during and after giving birth) }\end{array}$ & 2 & $-1^{* *}$ & 2 \\
\hline 23 & $\begin{array}{l}\text { There was no a choice about who or how many people kept my company during } \\
\text { childbirth (i.e. my partner or other relative or friend) }\end{array}$ & 1 & 1 & 3 \\
\hline 24 & There is a need to stay at home for the traditional 40 days after having a baby & 1 & -1 & 3 \\
\hline 25 & My care provider explored adequately with me my contraceptive needs & -3 & -3 & -2 \\
\hline 26 & $\begin{array}{l}\text { Care providers gave adequate attention to women's pain and its relief during } \\
\text { childbirth }\end{array}$ & $-4^{* *}$ & -1 & 0 \\
\hline 27 & Health expenditure related to childbirth causes financial burden on my family & 1 & 1 & $-2^{* *}$ \\
\hline 28 & I was very satisfied with the hygiene aspect and the available facilities at the hospital & -1 & -1 & -1 \\
\hline 29 & $\begin{array}{l}\text { The possibility of having a male doctor in labour room makes me dislike having my } \\
\text { baby in the hospital }\end{array}$ & 3 & $-2^{*}$ & 3 \\
\hline 30 & I had all my babies at the hospital & $2^{* *}$ & $4^{* *}$ & $1^{*}$ \\
\hline 31 & Care providers need to be more tolerant with us & 2 & $3^{*}$ & 1 \\
\hline 32 & $\begin{array}{l}\text { Care providers in the labour room got angry with patients and did not deal with } \\
\text { them politely }\end{array}$ & -1 & $\mathbf{0}$ & -1 \\
\hline 33 & I sometimes had problems understanding what my care providers were saying to me & -1 & 1 & -1 \\
\hline 34 & No one explained what was happening or what the options were in hospital & 1 & 1 & -1 \\
\hline
\end{tabular}




\begin{tabular}{|c|c|c|c|c|}
\hline \multirow[t]{2}{*}{$\#$} & \multirow[t]{2}{*}{ Statement } & \multicolumn{3}{|c|}{ Factor } \\
\hline & & 1 & 2 & 3 \\
\hline 35 & The labour room was very crowded & $1^{* *}$ & $-3^{* *}$ & $0^{* *}$ \\
\hline 36 & It was very difficult to complain during and after childbirth & $\mathbf{0}$ & $\mathbf{0}$ & $\mathbf{0}$ \\
\hline 37 & $\begin{array}{l}\text { For postnatal care, it is important to see the same midwife that I had in the antenatal } \\
\text { period }\end{array}$ & 3 & 2 & $1^{*}$ \\
\hline 38 & $\begin{array}{l}\text { I was given enough advice and help about my own health and recovery after birth } \\
\text { during postnatal care visits }\end{array}$ & 0 & -1 & $-4^{* *}$ \\
\hline 39 & The materials and tools used by care providers during labour were clean & $\mathbf{0}$ & $\mathbf{0}$ & 0 \\
\hline
\end{tabular}

${ }^{*}$ Distinguishing statement significant at $P<0.05 ;{ }^{* *}$ Distinguishing statement significant at $P<0.01$. Bold type indicates consensus statements.

Erbil and 7 with intermediate to secondary-school education. Factor 1 reflected a general perception of poor childbirth and postnatal care with lack of appropriate interpersonal care and support. The respondents emphasized poor childbirth and postnatal care as they considered childbirth the worst experience of their lives and indicated that the labour room was very crowded. They complained about poor interpersonal care and poor attention received from care providers, as they thought that the care providers at the hospital were too busy to take proper care of them and did not give adequate attention to women's pain and its relief during labour. These women had concerns about the lack of provision of adequate advice and help about feeding and looking after the baby while they were in the hospital for childbirth, and about the lack of good monitoring of woman's recovery after childbirth. They did not think that it would have been better if they had had a longer hospital stay after childbirth.

The responses indicated a lack of interpersonal support from staff, as respondents had concerns about never having met beforehand any of the doctors or midwives who looked after them during labour and they emphasized the importance of seeing the same midwife for postnatal care that they had in the antenatal period.

Women loading on this factor also showed a general concern about lack of adequate emotional support during childbirth and postnatal care. They disagreed with the statements that their husband was of the best possible help after the baby was born and least agreed with the statement that they had made skin-to-skin contact with the baby either immediately or soon after birth.

\section{Factor 2: Confident and well- supported}

Three participants loaded significantly onto factor 2 . All the women resided in affluent quarters in Erbil and included 2 women who were employed and 2 with college-level education. Factor 2 reflected the experiences of confident and well-supported women who had high satisfaction with the childbirth and postnatal care services. Compared with other factors, the women loading on this factor had a high satisfaction with the childbirth and postnatal care services. They least agreed with the statements that childbirth was one of the worst experiences of their lives, that the labour room was very crowded and that the care providers were usually too busy at the hospital to take care of them properly. They did not agree that there was only 1 doctor at the labour ward who was in rush and was moving from one patient to another. They were also satisfied with the immediate postnatal care services, as they indicated that they were given enough advice and help about feeding and looking after the baby while they were in the hospital for labour. All these women had their babies at hospital and preferred giving birth at hospital rather than at home or with a traditional birth attendant.

These women seemed to be confident and well-supported as they indicated that their husbands were the best possible help to them after the baby was born and that skin-to-skin contact with the baby had occurred either immediately or soon after birth. They did not seem to be concerned at all about the importance of having a baby boy to having a better position within the family or about having a male doctor in labour room. These women did not agree with the statement that they were frequently left alone by the care providers at a stage when it worried them to be alone while they described the local primary healthcare centre as an important support to them after having a baby.

\section{Factor 3: Cultural traditions}

Nine participants loaded significantly onto factor 3. They included 6 housewives, 4 residing in poor quarters in Erbil and 6 with primary- to intermediate-school education. Factor 3 reflected some poor satisfaction with the childbirth and postnatal care services and a noticeable influence of traditional cultural practices on the women's views. These women seemed to be greatly influenced by traditional cultural practices, as they were concerned about the importance of following cultural traditions such as protecting the baby from the evil eye and eating special food 
and about the need to stay at home for the traditional 40 days after giving birth. They indicated that there was no a choice about who or how many people kept them company during childbirth. These women least agreed with the statement that they had had their babies at the hospital. They indicated that they would not return to the same hospital if they had another baby and that they preferred giving birth at home or with a traditional birth attendant rather than at hospital. The possibility of having a male doctor in the labour room made them dislike having their babies in the hospital.

\section{Consensus statements}

There were 10 consensus statements, i.e. their scores did not differ statistically across the different factors. Four of these statements showed agreement on: the need for more care providers (particularly nurses and midwives) in the labour ward; care providers' inadequate exploration of women's contraceptive needs; the lack of provision of adequate advice and help about woman's health and recovery after birth while at hospital; and dissatisfaction with hygiene and the facilities available at the hospital.

\section{Discussion}

This explorative study revealed 1 positive and 2 generally negative perspectives of women and their experiences of the childbirth and postnatal care services in Erbil. Factor 1 represented the women with poor satisfaction with childbirth and postnatal care services, whose their main concern was related to poor interpersonal care and support. Most of the respondents loading in this factor had low socioeconomic and educational status, which might explain their greater need for information and support. Poor satisfaction with the quality of care at facilities is an important barrier to maternity care. Care providers play an important role in determining the level of women's satisfaction with the quality of care. Poor usage of care might be related to lack of provision of socioculturally appropriate and respectful care by care providers, with women identifying these services as unsuitable or inadequate (25). Women's perceived quality of care and satisfaction with maternity care is largely associated with the availability of skilled and experienced staff, polite behaviour by staff and greater provider empathy $(25,26)$. A family-supportive environment during pregnancy and childbirth is essential to maximize favourable outcomes (27). Women's experience with childbirth and postnatal care is also influenced by the presence or lack of social, emotional and family support. For example, increased mother's satisfaction with the birth process and decreased need for pain medication have been found to be associated with childbirth supported by fathers (27).

Factor 2 represented the women with high satisfaction with the childbirth and postnatal care services which could be attributed to their being confident and well-supported. The generally high socioeconomic and educational status of these participants might also be responsible for their having such confidence and support. Feelings of confidence and autonomy are important features of responsibility, which is the main reason why women seek proper maternity services (28). Confident women are more likely to have the freedom to adhere or nor to adhere to traditions, whereas women who lack family support are more likely to feel pressure to adhere to these traditions (21). Family and professional support can have a positive effect on the maternity care experience of the mothers. When women feel unsupported by health-care professionals, they feel isolated and dissatisfied with maternity services $(21,29)$. Having the support of the husband and the wider family might help women to feel valued and to increase their self-esteem, which in turn will encourage their expectation of reasonable care (21).

Factor 3 represented the women who were noticeably influenced by traditional cultural practices. While traditions and culture affect all levels of society, they usually have greater influence on the less affluent and educated people. That is possibly why the respondents loading on this factor were mainly poorly educated and had poor socioeconomic status. Maternity health behaviour is usually embedded within specific social relations and cultural contexts. Culture plays a major role in the way a woman perceives and prepares for her birthing experience. An emphasis on culture as a barrier is evident in the literature on maternal health. Perpetuation of "false beliefs" are cited as major obstacles to improved maternal health (30). Cultural practices can affect woman in different ways (21). In most societies, including Iraq, there are cultural practices that can have negative effects on pregnancy outcomes (31). The importance of understanding cultural practices should be emphasized while remembering that each tradition might not be significant to every family. Therefore, it is important for care providers to be sufficiently aware of cultural aspects of maternity care. Such awareness can be provided by implementing cultural competency awareness training for care providers. We might also need to transform the educational curriculum, the training setting and the emphasis of education and training of care providers in order to achieve a more women-centred approach to maternity care. Moreover, sufficiently empowering women can have a positive impact on avoiding harmful cultural beliefs and practices.

The presence of differences in viewpoints of women about maternity services in Iraq, and in particular about childbirth and postnatal care, is well-recognized and is expected. This is particularly true when the respondents receive maternity services at different 
service delivery points with different quality of care and health professional with different skills. Q-methodology can help in uniquely identifying and highlighting such differences in a new and insightful way $(7,10)$. There can be many possible reasons for differences between the respondents in their experience of care. For example, the sociodemographic characteristics of the participating women such as education level, employment status and economic status might influence their perception of the quality of care. Women's previous experience with childbirth or lack of it and the specific circumstances of their experience are other possible explanations for these different viewpoints (32).

Interestingly, the women in the 3 different groups had a general consensus on a wide range of issues concerning childbirth and postnatal care. Such a consensus was largely related to poor provision of information, poor communication, inadequate staffing, negative attitude of the providers and poor hygiene aspects of the facilities and tools. Studies on women's satisfaction with childbirth and postnatal care frequently emphasize the importance of provision of information, difficulty in getting individualized information and breastfeeding support, lack of encouragement and response to personal questions and poor attention to the mothers (33).

Q-methodology is exploratory in nature and can provide a useful insight into the available viewpoints in society and a characterization of each viewpoint. Q-studies are generally not meant to be generalizable or to determine the proportion of respondents that hold particular viewpoints. Therefore, they usually include a small number of participants (34). However, they might provide an initial understanding of the sociodemographic characteristics associated with each viewpoint. As a hypothesis-generating tool, Q-methodology can be followed up with larger surveys to examine these uncovered viewpoints and their associated factors (35).

This study revealed different patterns of viewpoints and experiences of Iraqi women of the childbirth and postnatal care services and highlighted some specific issues related these patterns. A breadth of viewpoints and experiences was identified that might primarily be related to the degree of interpersonal care received, family support and traditional culture. While some women were satisfied with some aspects of the available services, satisfaction with many important aspects of care remained poor among different groups of the women. This study suggests that the childbirth and postnatal care of these women needs substantial improvement particularly in term of providers' skills and attitude and the wider sociocultural environment. However, our findings merely represent the perspectives of the respondents and further research around assessing women's needs in this area is deemed necessary. Such needs assessment should particularly focus around providers' skills and interactions with patients and empowering and supporting women throughout the childbirth and postnatal period.

Funding: None.

Competing interests: None declared.

\section{References}

1. Making a difference in countries. Strategic approach to improving maternal and newborn survival and health: Ensuring skilled care for every birth. Geneva: World Health Organization; 2006.

2. Maternal mortality. Fact sheet No. 348 [Internet]. Geneva: World Health Organization; 2014 (www.who.int/mediacentre/factsheets/fs348/en, accessed 19 July 2015).

3. The world health report: 2005: make every mother and child count. Geneva: World Health Organization; 2005.

4. Smith LFP. Postnatal care: development of a psychometric multidimensional satisfaction questionnaire (the WOMBPNSQ) to assess women's views. Br J Gen Pract. 2011 Oct;61(591):e628-37. PMID:22152835

5. Ali MM, Shah IH. Sanctions and childhood mortality in Iraq. Lancet. 2000 May 27;355(9218):1851-7. PMID:10866440

6. Alwan AD. [Health-sector funding: options for funding health care in Iraq] [in Arabic]. East Mediterr Health J. 2008 NovDec;14(6):1372-9. PMID:19161113

7. Shabila NP, Al-Tawil NG, Al-Hadithi TS, Sondorp E. The range and diversity of providers' viewpoints towards the Iraqi primary health care system: an exploration using Q-methodology. BMC Int Health Hum Rights. 2013;13:18. PMID:23514334

8. Alwan A. Health in Iraq: The current situation, our vision for the future and areas of work. 2nd ed. Baghdad: Ministry of Health; 2004.
9. Iraq: reproductive health assessment. Baghdad: United Nations Population Fund; 2003.

10. Shabila NP, Ahmed HM, Yasin MY. Women's views and experiences of antenatal care in Iraq: a Q methodology study. BMC Pregnancy Childbirth. 2014;14:43. PMID:24450437

11. Iraq: Country statistics summary. Cairo: World Health Organization Regional Office for the Eastern Mediterranean (http:// rho.emro.who.int/rhodata/node.country.country-IRQstats?lang=en, accessed 19 July 2015).

12. Quinn J. Letter from the field: health security in Kurdistan. J Hum Secur. 2011;7(2):47-53.

13. Chinnis AS, Summers DE, Doerr C, Paulson DJ, Davis SM. Q methodology: a new way of assessing employee satisfaction. J Nurs Adm. 2001 May;31(5):252-9. PMID:11388161

14. Davis $\mathrm{CH}$, Michelle C. Q methodology in audience research: bridging the qualitative/quantitative 'divide'? Participations: Journal of Audience and Reception Studies. 2011;8(2):559-93.

15. Brown SRQ. Methodology. In: Given Im, editor. the sage encyclopedia of Qualitative Research Methods. Thousand Oaks (CA): Sage; 2008.

16. Karim K. Q methodology-advantages and the disadvantages of this research method. J Community Nurs. 2001;15(4):8-10.

17. van Exel NJA, de Graaf G. Q methodology: a sneak preview. 2005 (qmethod.org/articles/vanExel.pdf, accessed 19 July 2015). 
18. Smith NW. Current systems in psychology: history, theory, research, and applications. Belmont (CA): Wadsworth; 2001.

19. Perz J, Ussher JM, Gilbert E. Constructions of sex and intimacy after cancer: Q methodology study of people with cancer, their partners, and health professionals. BMC Cancer. 2013;13:270. PMID:23725590

20. Watts S, Stenner P. Doing Q methodology: theory, method and interpretation. Qual Res Psychol. 2005;14:67-91.

21. Raof AM. Safe motherhood needs assessment in Erbil city. Erbil, Iraq: Hawler Medical University; 2011.

22. Cross-Sudworth F, Williams A, Herron-Marx S. Maternity services in multi-cultural Britain: using $\mathrm{Q}$ methodology to explore the views of first- and second-generation women of Pakistani origin. Midwifery. 2011 Aug;27(4):458-68. PMID:21036439

23. Donabedian A. The quality of care. How can it be assessed? JAMA. 1988 Sep 23-30;260(12):1743-8. PMID:3045356

24. Schmolck P. PQMethod Q methodology analysis program. 2002 (http://schmolck.userweb.mwn.de/qmethod/downpqwin.htm, accessed 21 July 2015).

25. Ith P, Dawson A, Homer CSE. Women's perspective of maternity care in Cambodia. Women Birth. 2013 Mar;26(1):71-5. PMID:22722014

26. Bazant ES, Koenig MA. Women's satisfaction with delivery care in Nairobi's informal settlements. Int J Qual Health Care. 2009 Apr;21(2):79-86. PMID:19208648

27. Harrigan MP, Baldwin SM. Conception, pregnancy, and childbirth. In: Hutchison ED, editor. Dimensions of human behavior: the changing life course. Thousand Oaks (CA): Sage; 2008.

28. Luyben AG, Fleming VE. Women's needs from antenatal care in three European countries. Midwifery. 2005 Sep;21(3):212-23. PMID:15967548

29. Bowes AM, Domokos TM. Pakistani women and maternity care: raising muted voices. Sociol Health Illn. 1996;18:45-65.

30. Price NL, Hawkins K. A conceptual framework for the social analysis of reproductive health. J Health Popul Nutr. 2007 Mar;25(1):24-36. PMID:17615901

31. Ajiboye OE, Adebayo KA. Socio-cultural factors affecting pregnancy outcome among the Ogu speaking people of Badagry area of Lagos State, Nigeria. IJHSS. 2012;2(4):133-44.

32. Haines HM, Rubertsson C, Pallant JF, Hildingsson I. The influence of women's fear, attitudes and beliefs of childbirth on mode and experience of birth. BMC Pregnancy Childbirth. 2012;12:55. PMID:22727217

33. Rudman A, Waldenström U. Critical views on postpartum care expressed by new mothers. BMC Health Serv Res. 2007;7:178. PMID:17983479

34. Brown SR. Q methodology as the foundation for a science of subjectivity. Operant Subjectivity. 1995;18(1/2):1-16.

35. Amin Z. Q methodology-a journey into the subjectivity of human mind. Singapore Med J. 2000 Aug;41(8):410-4. PMID:11256352 